\title{
CREEP AT ELEVATED TEMPERATURES IN CHROMIUM- VANADIUM STEELS CONTAINING TUNGSTEN OR MOLYBDENUM
}

\author{
By William Kahlbaum ${ }^{1}$ and Louis Jordan
}

ABSTRACT

Determinations of creep at temperatures between $750^{\circ}$ and $1,100^{\circ} \mathrm{F}$. were made on two tungsten-chromium-vanadium and a molybdenum-chromiumvanadium steel. These steels were tested as tempered after mechanical working (rolling) and are compared with steels of similar compositions which had been oil quenched and tempered.

\section{CONTENTS}

Page

I. Introduction $\mathrm{Method}$ of testing 441

II. Method of testing

IV. Discussion and summary

\section{INTRODUCTION}

This paper reports the results of tests of creep in tension made on 3 alloy steels; namely, 2 tungsten-chromium-vanadium steels and 1 molybdenum-chromium-vanadium steel. The chemical compositions of these steels, their mechanical properties at room temperature, and the heat treatments to which they were subjected prior to testing are all listed in Table 1 . There are also included in Table 1 three additional steels (a tungsten-chromium-vanadium steel, a chromiummolybdenum, and a molybdenum-chromium-vanadium steel) which had been tested previously for creep. ${ }^{2} \quad$ These steels so closely resemble the steels tested in the present work as to make desirable a comparison of the results of creep tests of the two groups.

The two tungsten-chromium-vanadium steels of the present report differ chiefly in carbon content $(0.50$, and 0.38 per cent). One of the steels previously tested (EE1139) very closely duplicated the two tungsten-chromium-vanadium steels of this report, especially the higher carbon steel. The heat treatments, however, differed in the two cases. The two steels recently tested were simply tempered at a rather high temperature after rolling, while the similar steel of the earlier work was oil quenched and tempered.

The third steel with which this report is primarily concerned is a molybdenum-chromium-vanadium steel (SE208) containing about 1.2 per cent manganese. This steel is compared with two of the steels previously tested, of which one (E1549) was of a very similar composition, also with high manganese ( 0.95 per cent) but without vanadium; the other was also similar to steel SE208 of the present report, except that this comparison steel (E1490) was of higher carbon and lower manganese content.

1 Research associate, representing The Midvale Co., Philadelphia, $\mathrm{Pa}$.

2 H. J. French, William Kahlbaum, and A.A. Peterson, Flow Characteristics of Special Fe-Ni-Cr Alloys and Som $\theta$ Steels at Elevated Temperatures, B. S. Jour. Research, vol. 5 (RP192), p. 125, 1930. 


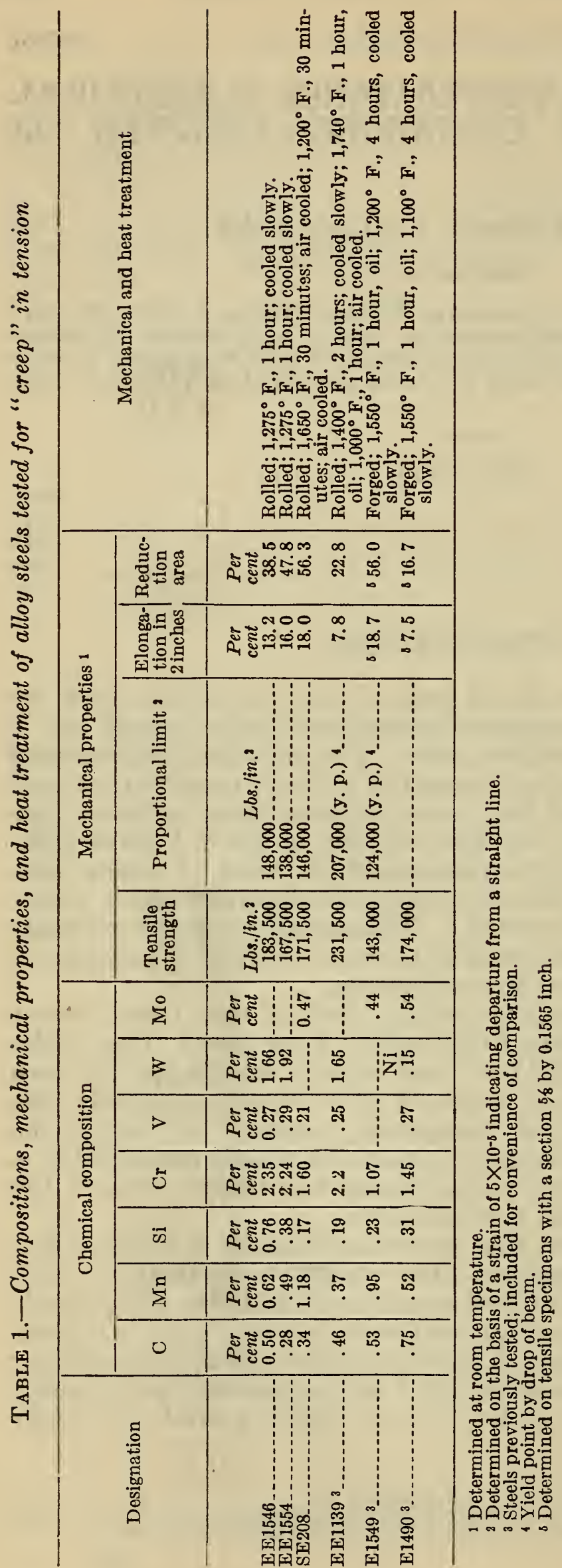




\section{METHOD OF TESTING}

The method employed for determining "creep" was substantially the same as previously described, ${ }^{3}$ except that all of the horizontal furnaces and loading machines were replaced by vertical units, as shown in Figure 1. As a result the frictional losses of the mechanical lever loading system were materially reduced.

Figure 1 shows the method of loading the specimen in the vertical furnace. The specimen was 0.250 inch in diameter within the 2-inch gage length. The top adapter was suspended from a spherical seat.

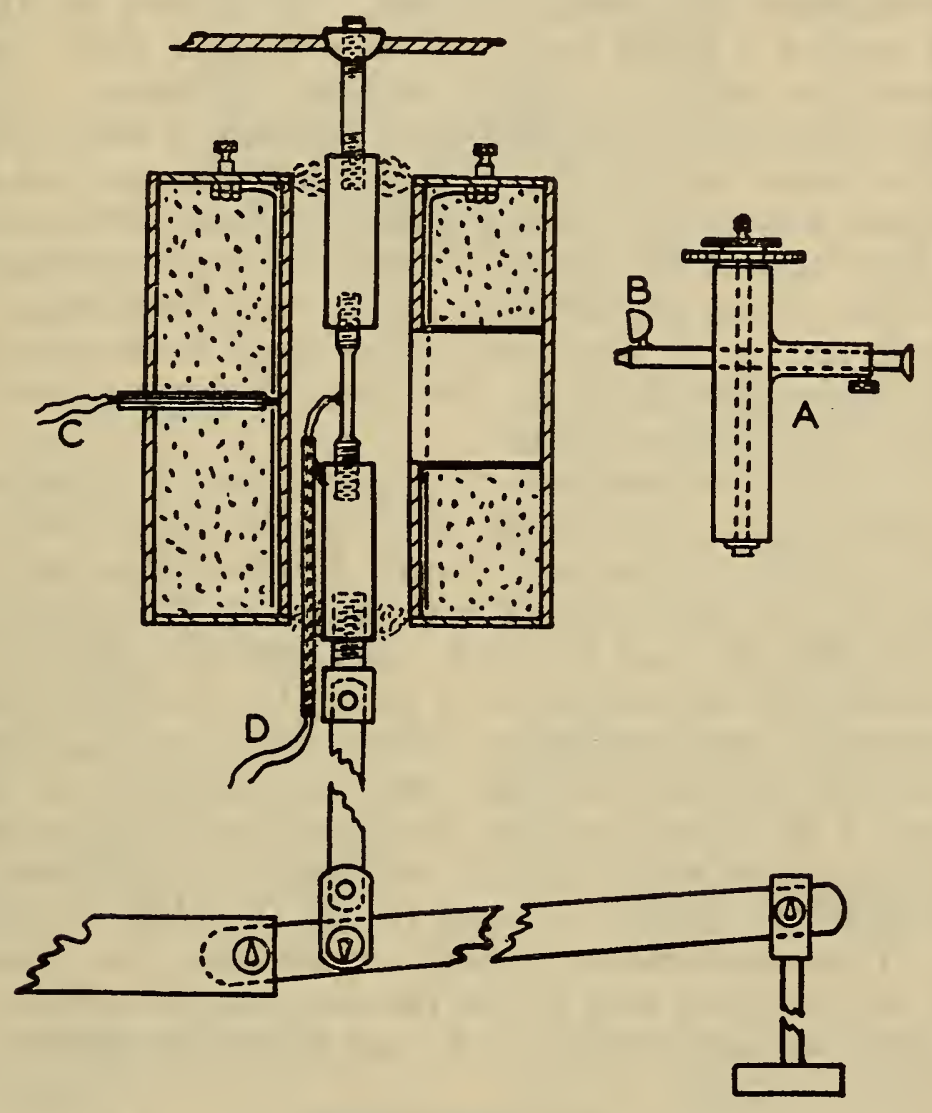

Figure 1.-Diagram of vertical test units for creep tests at elevated temperatures

$A$, traveling microscope; $B$, lamp; $C$, furnace control thermocouple; $D$, specimen temperature thermocouple.

The temperature of the specimen was measured by the thermocouple $D$, the hot junction of which was tightly wired to the surface of the specimen at the middle of the gage length. An automatic temperature control which regulated the temperature of the furnace was actuated by the thermocouple $C$, the hot junction of which was placed close to the furnace windings. During operation the top and bottom openings of the furnace around the adapters were tightly packed with asbestos to minimize convection currents within the furnace. A narrow rectangular opening through one side of the furnace (covered except when actually observing the gage marks) permitted measurements of the extension of the specimen during testing.

The gage length of the specimen was defined by cutting a shallow groove close to the fillet at each end of the reduced section of the 
specimen and securing tightly in this groove a loop of $32 \mathrm{~B} . \& \mathrm{~S}$. gage (0.008 inch diameter) platinum wire. The coefficient of expansion of platinum being less than that of steel, the wire did not loosen as the temperature rose.

The expansion was observed by means of a traveling microscope of long focus ( $A$, fig. 1 ) whose motion was governed by a screw of $0.5 \mathrm{~mm}$ pitch and a disk carrying 100 divisions. The value of one division on the disk was, therefore, $0.005 \mathrm{~mm}\left(2 \times 10^{-4}\right.$ inch).

The accuracy of the readings depended considerably on the illumination, and therefore the illumination was kept as constant as possible throughout the period of test. As shown in Figure 1, the microscope carried a small lamp, $B$, so arranged that the rays were reflected from the wire at nearly normal incidence. Through the telescope the illuminated spot appeared pointed at each end, and upon the points the cross hair of the traveling microscope was set.

Observations were made over a period of from 400 to 1,000 hours, usually at intervals of 24 hours. In the case of specimens carrying the lower loads at any temperature, there was frequently insufficient creep in 24 hours to be detected. The total creep over periods of 400 to 1,000 hours permitted the detection of creep rates of the order of $10^{-6}$ inches per inch per hour.

A survey of the temperature uniformity of the specimen showed that the temperature indicated by the thermocouple, $D$, at the surface of the middle of the gage length differed from the temperature at the center of the specimen at the midpoint of the gage length by only $1^{\circ} \mathrm{F}$. at $800^{\circ} \mathrm{F}$. and by $3^{\circ} \mathrm{F}$. at $1,200^{\circ} \mathrm{F}$. Furthermore, the maximum variation in temperature along the length of the test bar (the temperature measurements being made at the ends of the specimen in the shoulder of the bar just outside of the reduced section) was in all cases greatest between the bottom end and the middle of the gage length. This difference amounted to $23^{\circ} \mathrm{F}$. $\left(13^{\circ}\right.$ C. $)$ at $800^{\circ} \mathrm{F} .\left(426^{\circ}\right.$ C. $)$ and to $18^{\circ} \mathrm{F} .\left(10^{\circ}\right.$ C. $)$ at $1,200^{\circ} \mathrm{F}$. $\left(648^{\circ}\right.$ C.). The temperature difference between the middle of the gage length and the top end of the bar was not detectable at $800^{\circ} \mathrm{F}$. $\left(426^{\circ} \mathrm{C}\right.$.), and was only $9^{\circ} \mathrm{F}$. $\left(5^{\circ} \mathrm{C}\right.$.) at $1,200^{\circ} \mathrm{F}$. $\left(648^{\circ} \mathrm{C}\right.$.).

\section{RESULTS}

The time-extension curves for the three steels, showing on each curve the stress in lbs./in. ${ }^{2}$ of original cross section and, in parentheses, the identification number of the specimen, are given in Figures 2, 3, and 4. The two tungsten-chromium-vanadium steels were tested at $750^{\circ}, 850^{\circ}, 950^{\circ}, 1,050^{\circ}$, and $1,100^{\circ} \mathrm{F}$; the single molybdenumchromium-vanadium steel at $650^{\circ}, 850^{\circ}$, and $1,050^{\circ} \mathrm{F}$.

In Figures 5, 6, and 7 are plotted for the several testing temperatures the stress and the initial flow; that is, the relatively rapid deformation at the time of, or immediately after, loading. Also, there are plotted the stress and the average rates of flow, calculated from the so-called second stage of the time-extension curves; that is, that portion of rather uniform rate of extension following the initial flow.

Figures 8,9 , and 10 show the stress which, at any selected temperature, results in $0.1,1,2$, or 5 per cent secondary elongation, or creep, in 1,000 hours. These figures also show in some cases the stress resulting in $0.1,1$, or 2 per cent initial elongation preceding the stage of secondary elongation. 


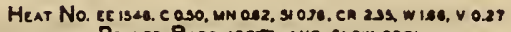
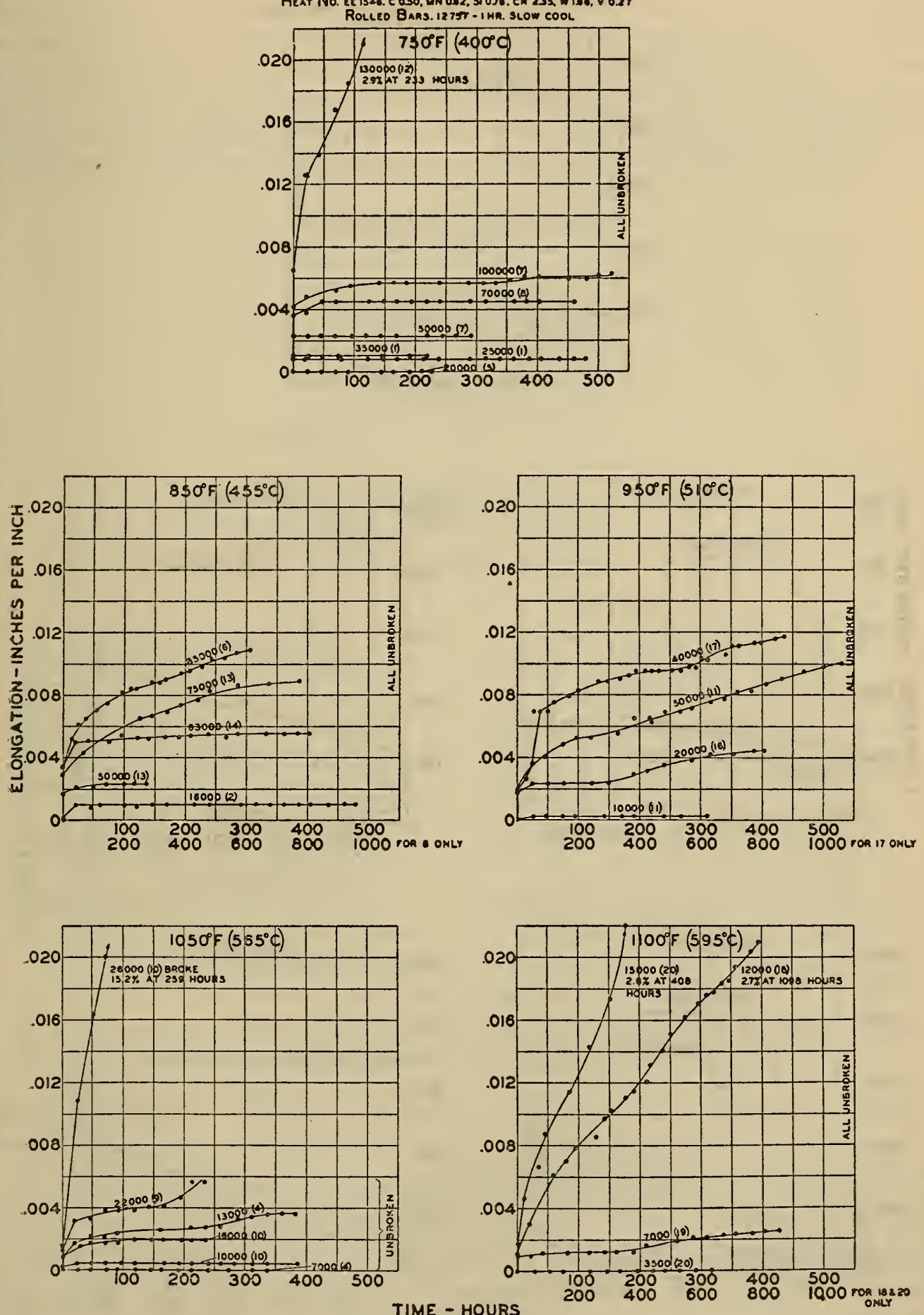

TIME - HOURS

FIGURE 2.-Time-elongation curves of tungsten-chromium-vanadium steel EE15 46 under different loads and at different temperatures 
HeAt No. ce issa. C 0.20, MN aAs, su oss, en 2.24, w 192, v 0.24
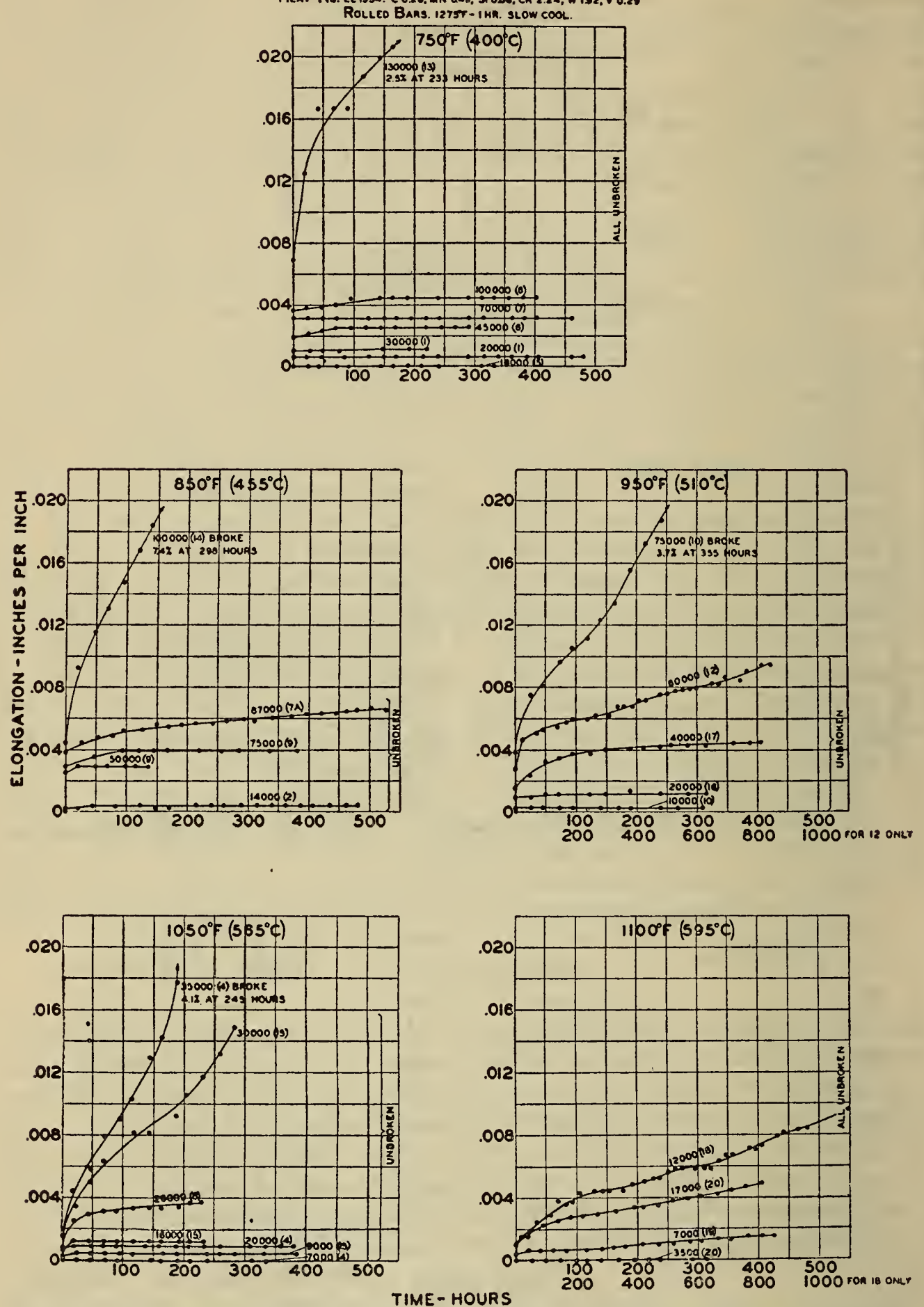

FIGURE 3.-Time-elongation curves of tungsten-chromium-vanadium steel EE1554 under different loads and at different temperatures 


\section{DISCUSSION AND SUMMARY}

The discussion of the results of the present creep tests and correlation of these results with previously tested steels of similar compositions is most conveniently based on Figure 11. In this figure the top and bottom of a solid black rectangle indicate, respectively, the stress producing 1 per cent and 0.1 per cent initial deformation. When there is given only a small solid triangle, the base of the triangle indicates the stress producing 0.1 per cent deformation and there is no value for 1 per cent deformation. Similarly, the open (light) rec-
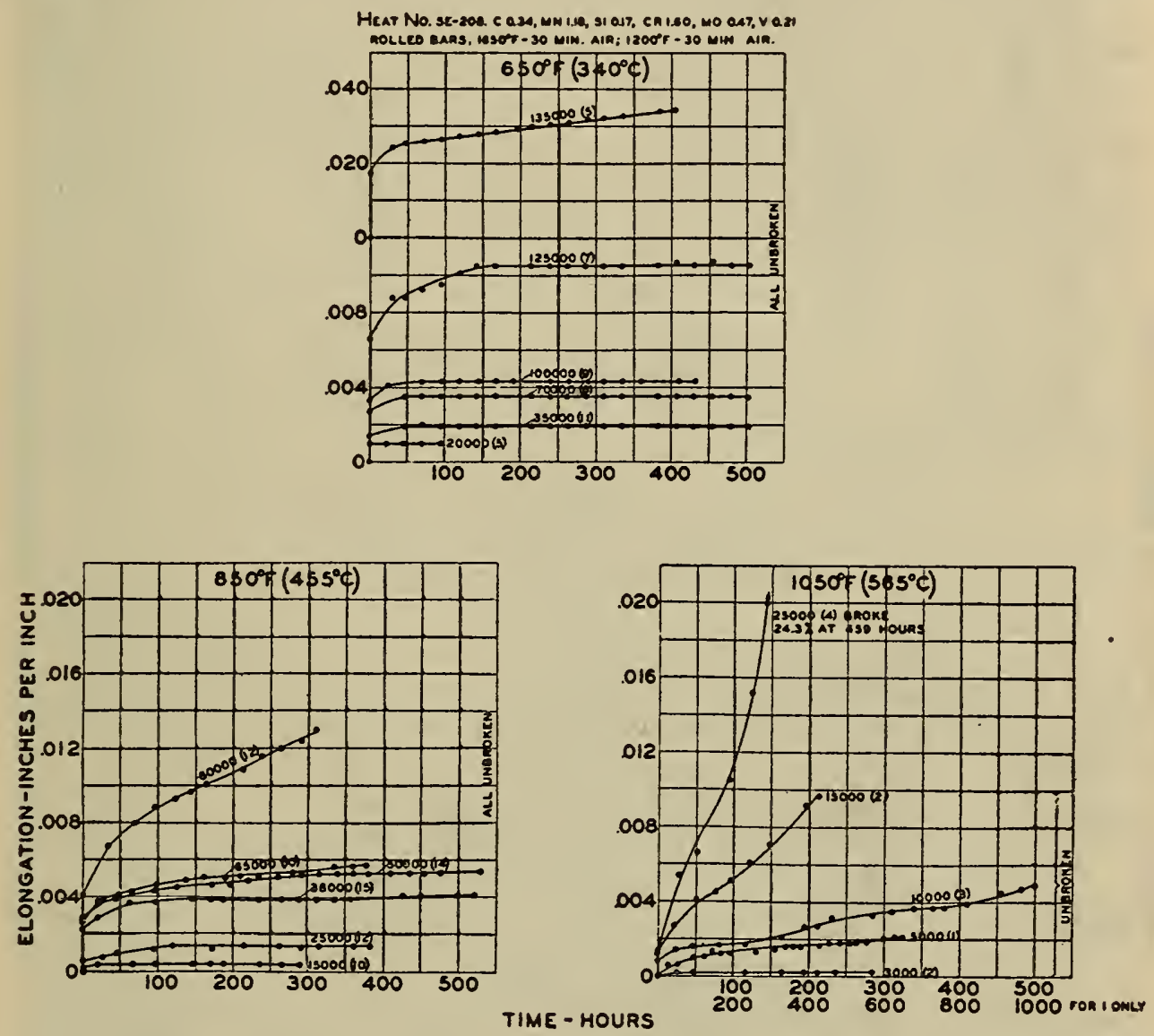

FIGORE 4.-Time-elongation curves of molybdenum-chromium-vanadium steel SE208 under different loads and at different temperatures

tangles indicate secondary flow in 1,000 hours of 1 per cent and 0.1 per cent.

A comparison of the two tungsten-chromium-vanadium steels of the present tests (EE1546 and EE1554) shows that appreciably higher stresses are sustained by the steel of lower carbon content (EE1554) at $860^{\circ}, 950^{\circ}$, and $1,000^{\circ} \mathrm{F}$. before 0.1 or 1 per cent creep results than is the case with the higher carbon steel. Also there is for the lower carbon steel a wider range at $950^{\circ}$ and $1,000^{\circ} \mathrm{F}$. between the stresses producing 0.1 and 1 per cent creep than for the higher carbon steel.

The previously tested tungsten-chromium-vanadium steel (EE1139) was oil hardened and tempered before testing, while steel EE1546 of very similar composition was simply tempered after rolling. From Figure 11 it appears that at the higher testing temperatures, $950^{\circ}$ 


\section{ALLOY EE 1546}

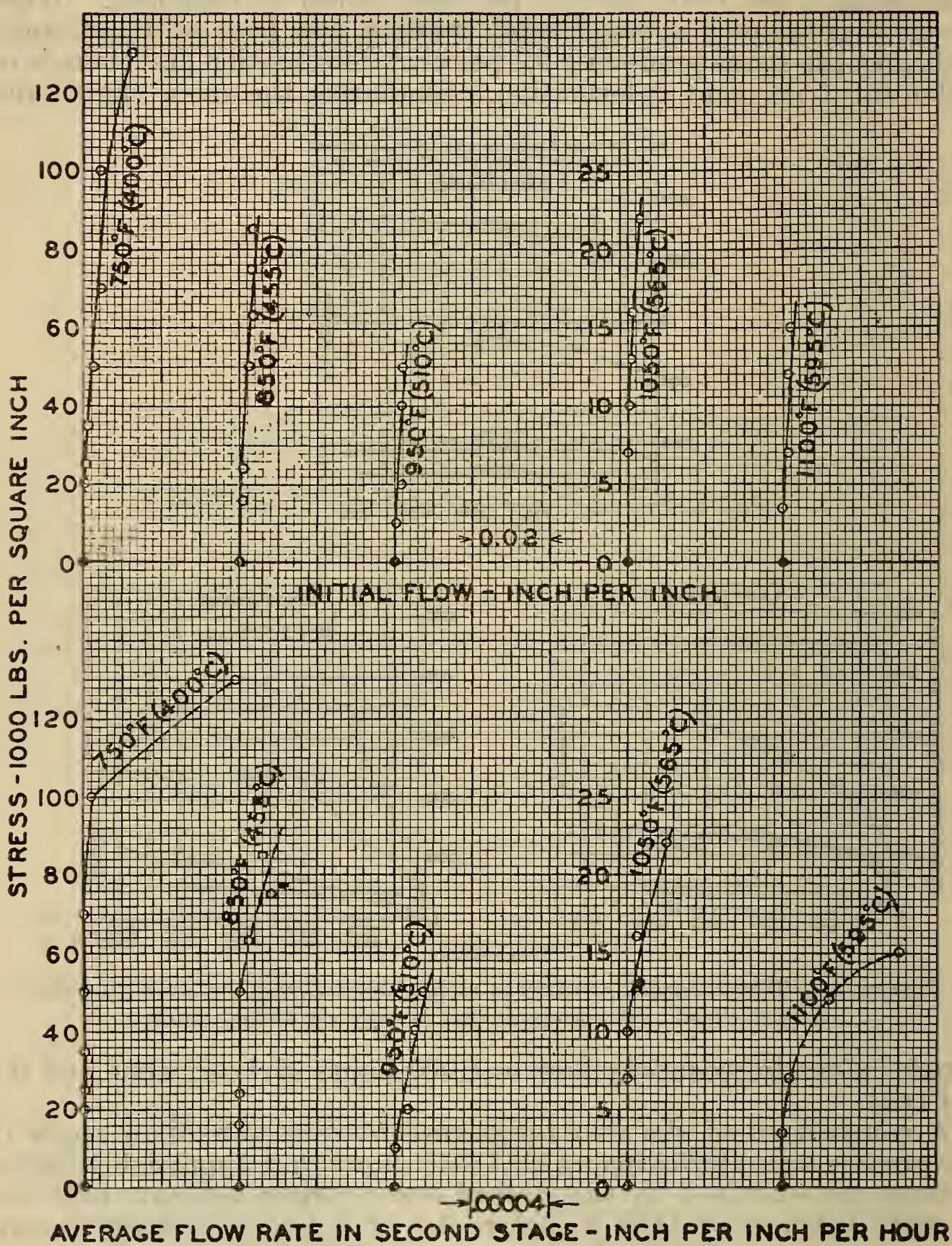

FIGURE 5.-Flow data for tungsten-chromium-vanadium sieel EE15 46 at different temperatures 


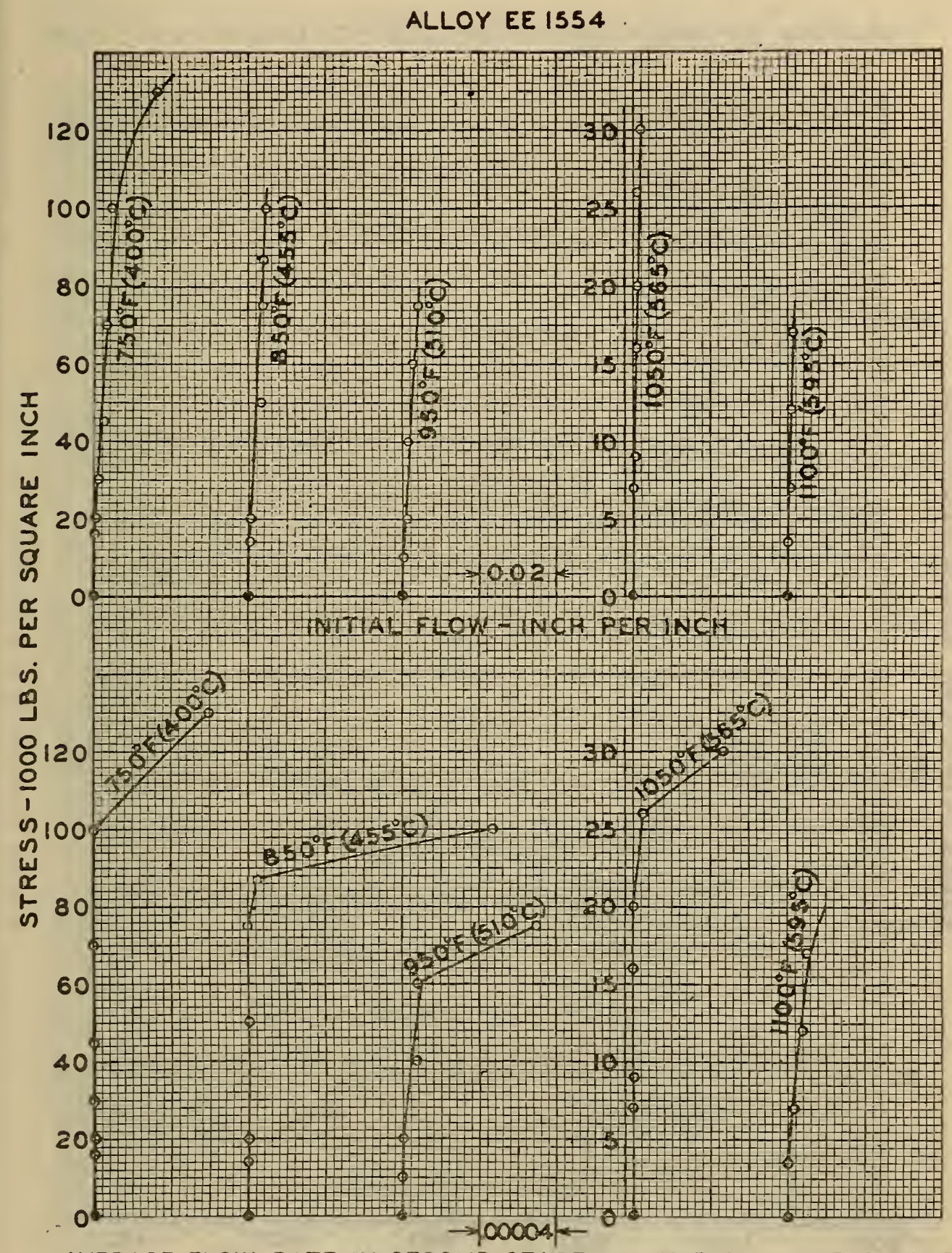

AVERAGE FLOW RATE IN SECOND STAGE - INCH PER INCH PER HOUR

Figure 6.-Flow data for tungsten-chromium-vanadium steel EE1554 at different temperatures 
HEAT NO. SE-203. C 0.34, MN 1.18, S1 0.17, CR 1.60, MO 0.47, V 0.21 ROLLED BARS. $1650^{\circ} \mathrm{F}-30 \mathrm{MIN}$. AIR; $1200^{\circ} \mathrm{F}-30 \mathrm{MIN}$. AIR.

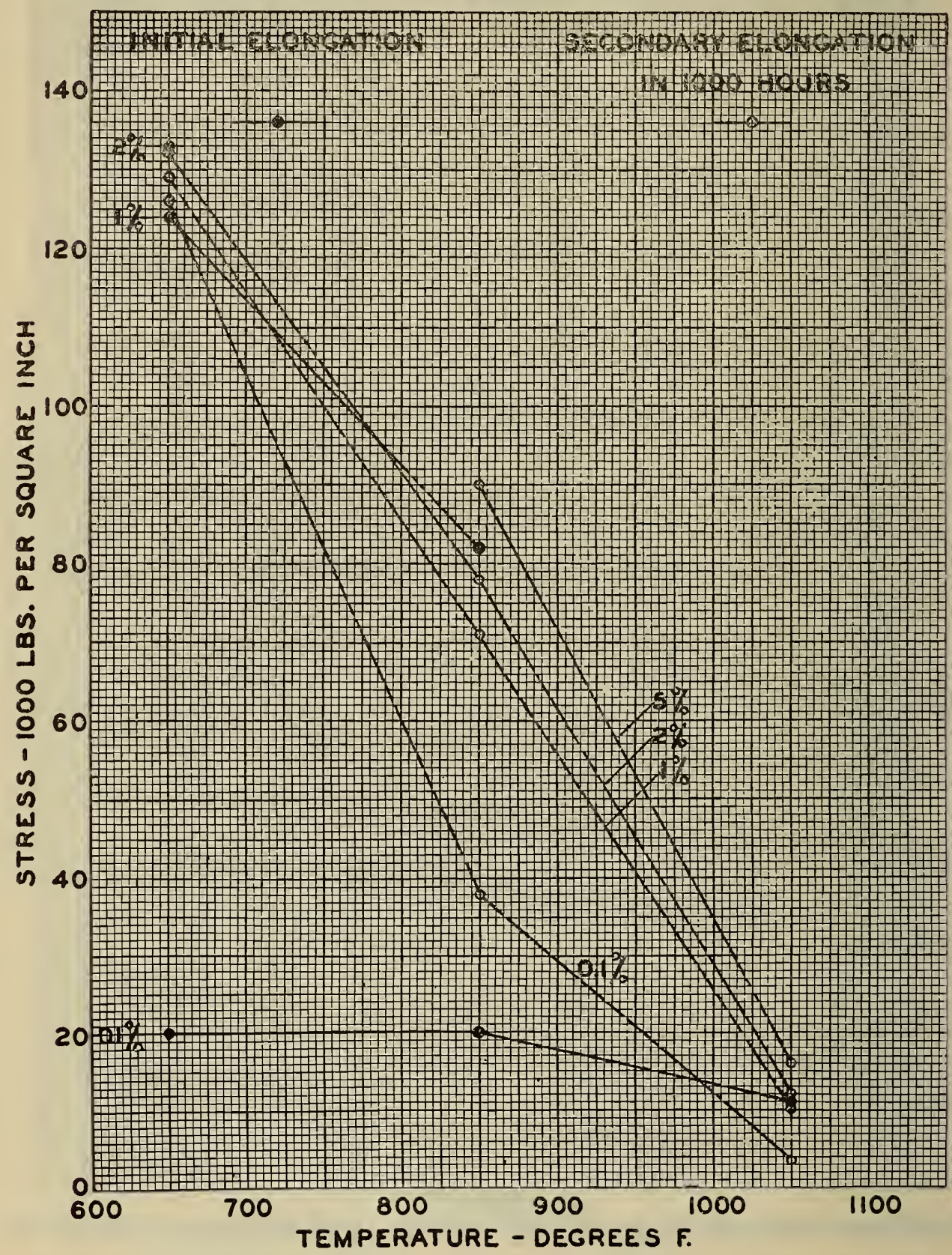

Figure 7.-Flow data for molybdenum-chromium-vanadium steel SE208 at different temperatures 
HEAT NO. EE 1546. C 0.50, MN 0.62, SI 0.76, CR 2.35, W 1.66, V 0.27 ROLLED BARS. $1275^{\circ} \mathrm{F}-1 \mathrm{HR}$. SLOW COOL.

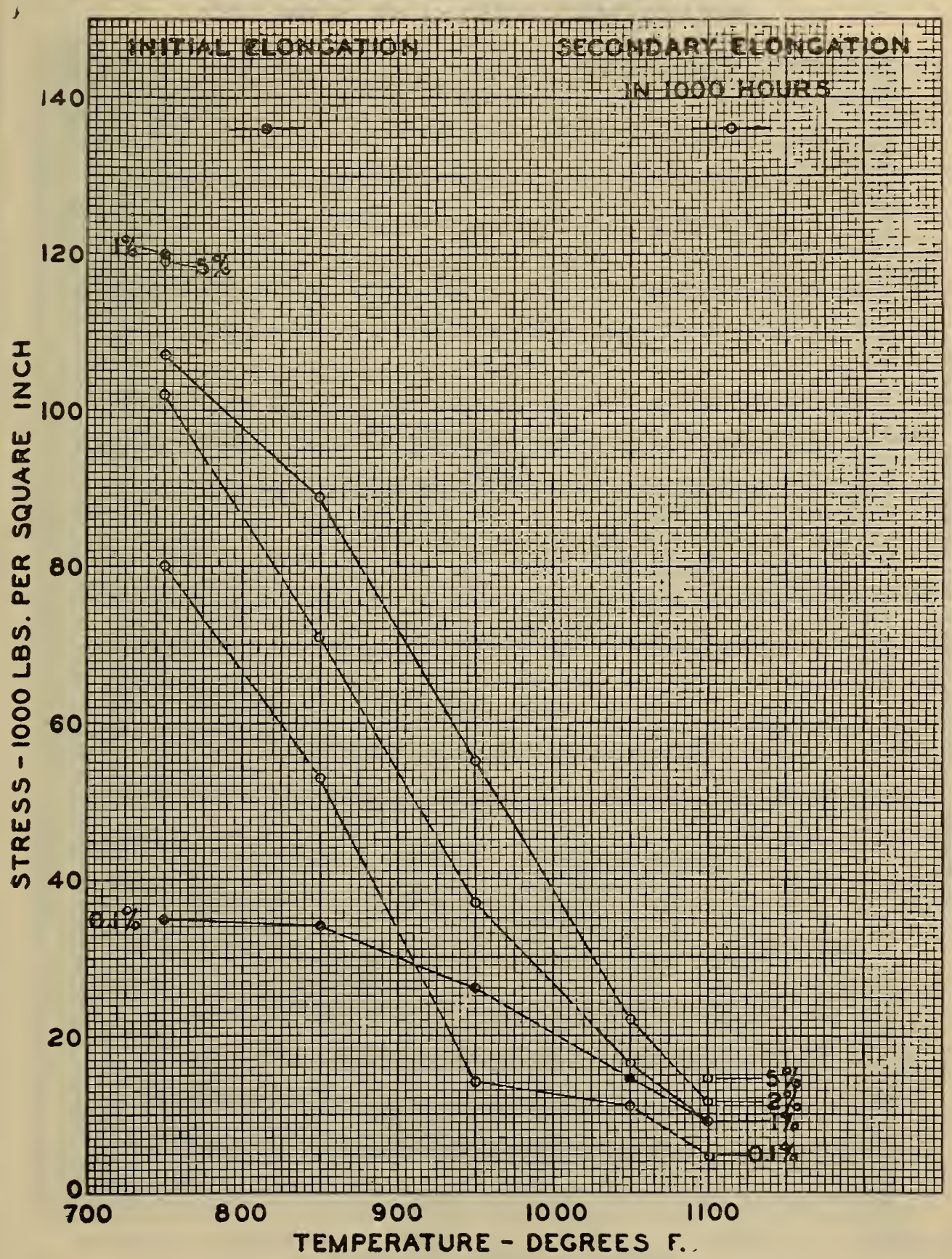

FIGURE 8.-Flow chart for tungsten-chromium-vanadium steel EE1546 at elevated temperatures 
HEAT NO. EE 1554. C 0.28, MN 0.49, SI 0.38, CR 2.24, W 1.92, V 0.29 ROLLED BARS. $1275^{\circ} \mathrm{F}-1$ HR. SLOW COOL.

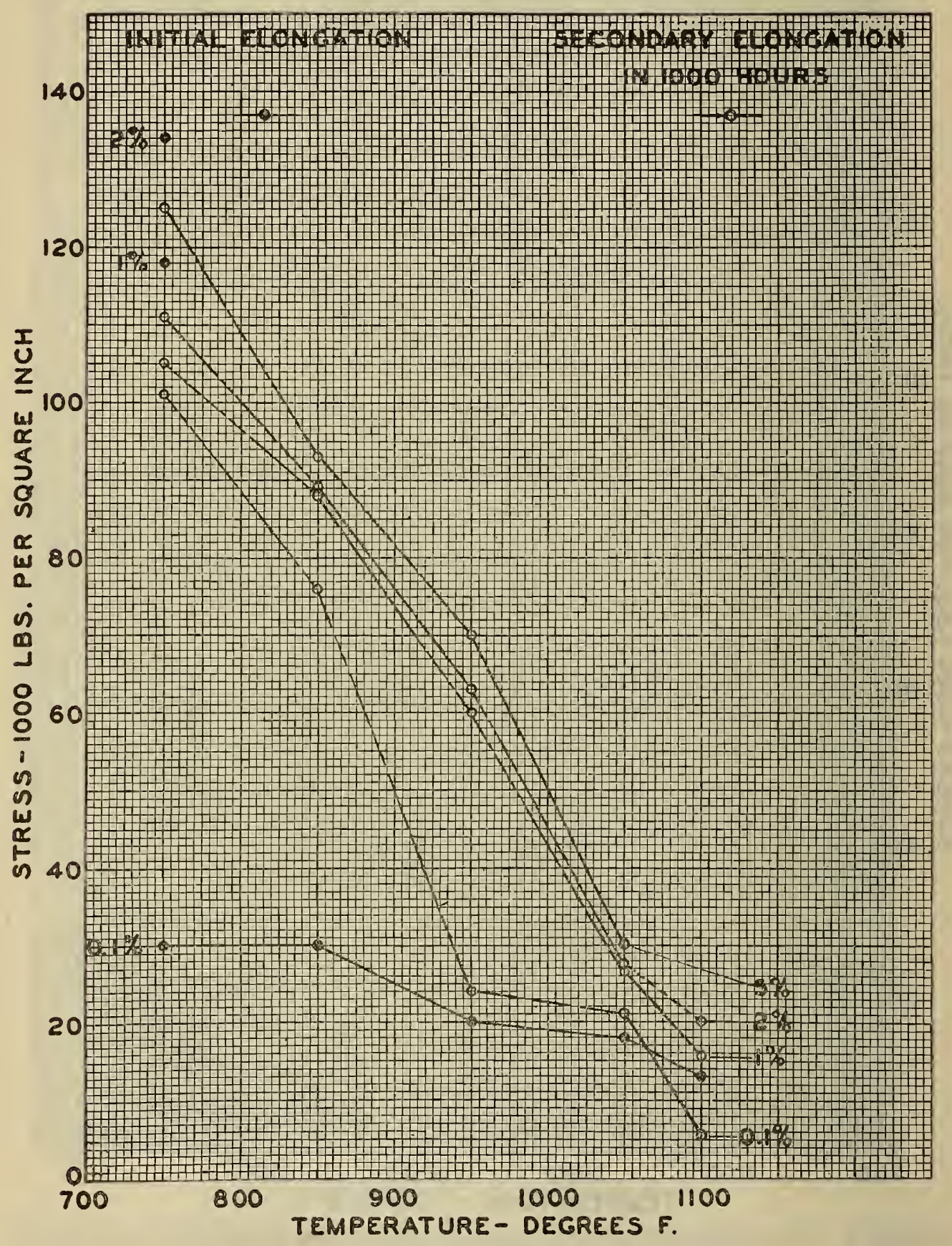

FIgURE 9.-Flow chart for tungsten-chromium-vanadium steel EE1554 at elevated temperatures 
ALLOY SE- 208

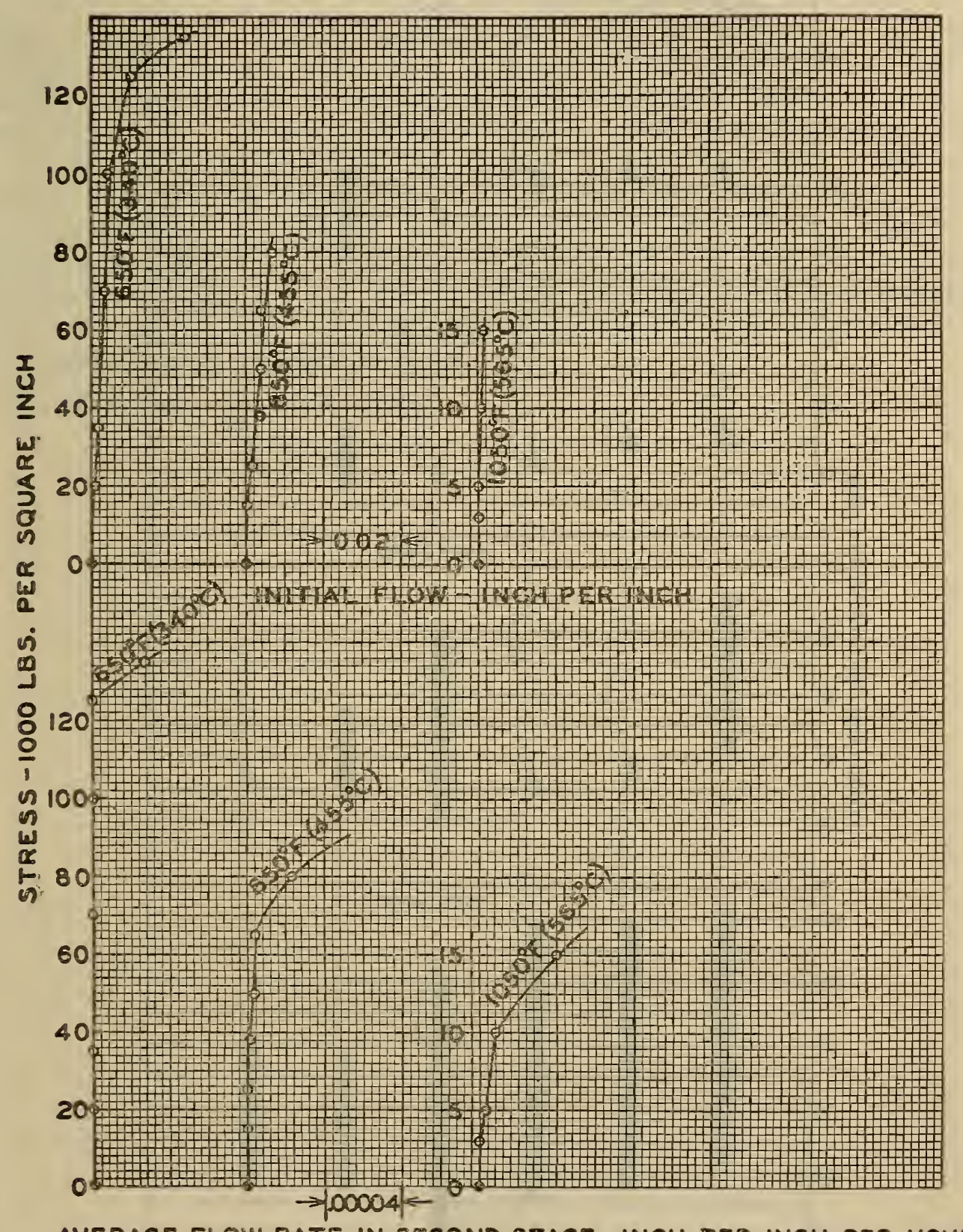

AVERAGE FLOW RATE IN SECOND STAGE - INCH PER INCH PER HOUR

FIGURE 10.-Flow chart for molybdenum-chromium-vanadium steel $S E 208$ $132919-32-12$ at elevated temperatures 


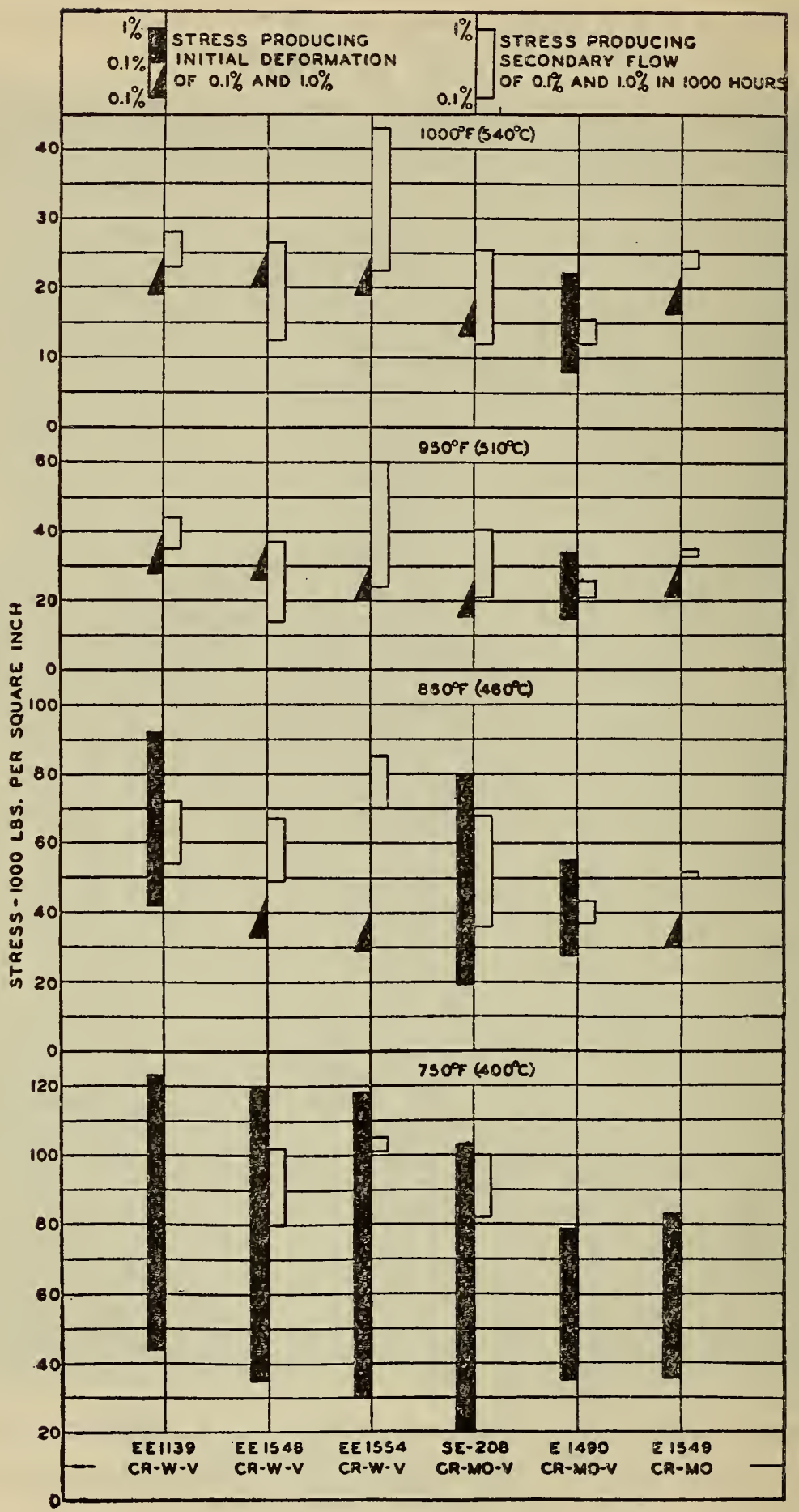

FIgURE 11.-Comparison of steels on the basis of the stresses producing both initial deformation and secondary flow (secondary flow is over period of 1,000 hours) 
and $1,000^{\circ} \mathrm{F}$., the stress producing 0.1 per cent creep was appreciably higher in the quenched and tempered steel. However, this hardened and tempered steel showed 1 per cent creep at stresses very much lower than the corresponding rolled-and-tempered steel (EE1554) at $860^{\circ}, 950^{\circ}$, and $1,000^{\circ} \mathrm{F}$.

The other comparison to be made in Figure 11 is between the two molybdenum-chromium-vanadium steels, SE208 (normalized and tempered) and E1490 (oil quenched and tempered), the latter steel being considerably higher in carbon and lower in manganese than the former. The greater resistance to creep of the lower carbon higher manganese steel at all of the testing temperatures involved is obvious from Figure 11. It has also a noticeably wider working range; that is, the range between stress producing 0.1 per cent and 1 per cent creep. The simple chromium-molybdenum steel, with about 1 per cent manganese, was found to have such narrow working ranges of stress as to suffer by comparison with steel SE208, even through the stresses producing 0.1 per cent creep in the chromium-molybdenum steel were appreciably higher at all temperatures than for the molybdenum-chromium-vanadium steel.

Washington, July 13, 1932. 